\title{
Mostly True Confessions: Joint Meaning-Making about the Thesis Journey
}

\author{
LYNN MCALPINE \& JOEL WEISS \\ McGill University \\ Ontario Institute for the Studies in Education \\ University of Toronto
}

\begin{abstract}
The thesis supervisory role is perhaps the most prominent, yet least understood, of a faculty member's teaching responsibilities. We retrospectively explore the doctoral supervisory experiences of a doctoral student and her thesis supervisor through the process of co-constructing a personal narrative of the journey. Our story addresses several assumptions of the thesis process: the dissertation is an original piece of research by the student; the supervisors in an arms-length relationship because the thesis is the intellectual property of the student; the supervisor and committee are experts while the student is a novice being introduced into the culture; the thesis process is the same regardless of the program and the goals of student and supervisor. We invite others to join our conversation by sharing stories of their experiences. By accumulating knowledge in an under-researched area, it is possible that higher education can improve its record of successfully completed doctoral dissertations.
\end{abstract}

\section{RÉSUMÉ}

La direction de thèse est peut-être la fonction la plus importante et la moins bien comprise des membres du personnel enseignant. Cet article examine rétrospectivement les expériences vécues par une étudiante de doctorat et son directeur de thèse par le biais de la reconstitution 
conjointe d'un récit personnel décrivant ce cheminement. Ce récit soulève plusieurs hypothèses quant au processus de préparation de la thèse: la thèse est un travail de recherche original de l'étudiant; la relation avec le directeur de thèse est fondée sur le principe d'autonomie, car la thèse est la propriété intellectuelle de l'étudiant; le directeur de thèse et le comité font figure d'experts, tandis que l'étudiant est un novice que l'on initie à la culture; le processus de préparation de la thèse est le même quel que soit le programme et les objectifs de l'étudiant et du directeur. Nous invitons les intéressés à se joindre au débat en nous faisant part de leurs expériences. L'avancement des connaissances dans ce domaine négligé par les chercheurs pourrait permettre d'accroître le nombre de thèses de doctorat menées à bien par les candidats.

\section{Vignette 1: Celebrating}

Joel (supervisor): There were changes taking place in the discourse in curriculum and I was aware of them and struggling with them... what really helped was Schon - reflective practitioner - had a major impact on me in terms of understanding the nature of what we do as researchers/academics/ technical rationalists, but also in starting to look at what we do - our own practice.

Lynn (graduate student): It was a very profound book for me too...I remember reading Schon and having this AHAA! experience - here was someone who in a different way was describing what I had been trying to name myself, to understand the principles driving my practice...

\section{Vignette 2: Struggling}

Lynn: I was still struggling with the idea that the academic world didn't necessarily validate my world of practice...I was having to do so much literature review to defend the decisions about the [dissertation] approach I was using... So one day we were sitting talking and I think I accused you of being unable to see through my eyes, unable to see my professional practice and the concerns I had around that and you responded quite irately - what did you say? 
Joel: I don't know if I was irate - I thought I was being as calm and collected as possible...But...I wanted to disagree with you..."you know there are different kinds of practice and right now we're participating in my practice and I think there are some connections - as a professor one has practices that deal with teaching and learning.

These vignettes give you a flavour of the diverse experiences shared by Lynn, a graduate student, and Joel, her supervisor, during the supervisor-supervisee relationship they shared.

Supervision has been the focus of a number of articles over the past few years in The Canadian Journal of Higher Education. This is not surprising given the critical role of the supervisor in socializing graduate students into the academic community: enabling students to complete their theses and dissertations, and through this process come to understand how to conduct research and participate in the culture of the academic.

In this paper we explore the nature of the supervisory relationship in the form of a co-constructed personal narrative about the supervisorgraduate student experience we shared in order to complete the dissertation. In doing so, we limit our use of the term supervisor to this one role, while recognizing that others such as Aguinis, Nesler, Quigley, Lee and Tedeschi (1996) define it in much broader terms. We also differentiate the supervisor role from that of the advisor The advisor role is usually assigned at the time students enter a program, and it entails advising students as to the academic choices and requirements they have to make/meet. The same individual may fulfill both the supervising and advising roles, but this is not necessarily the case.

\section{Rationale}

The major criteria for faculty rewards (i.e., tenure and promotion) in the academic world have been research, publications and success in grantsmanship. However, for some time now, there have been calls both publicly and institutionally for universities to emphasize excellence in teaching (e.g., Boyer, 1990; Smith, 1991). This focus is shared by many faculty members themselves. Centra (1991) reports on a study of 35,000 faculty in the United States in which $98 \%$ described being a good 
teacher as one of their goals. This focus on teaching has also led to calls to rethink and reconceptualize the role of teaching in the lives of professors. For instance, Shulman (1993) has called for teaching to be seen as community property; Edgerton, Hutchings and Quinlan (1991) have suggested teaching should be viewed as a scholarly activity; Centra (1991) and Braskamp and Ory (1994) echo these views, and others such as Daly (1994) have used the notion of aggregative scholarship to describe something similar. Personally, we find these ideas stimulating.

The suggestion that teaching can be seen as a scholarly activity just as much as the other responsibilities of the academic is well represented in Boyer's (1990) view that there are four integrated aspects to scholarship: discovery (research), integration (reorganization of that knowledge in ways that can be used by others, such as in a text), application (consulting or helping others because of our expertise), and lastly, teaching. Shulman (1993) helps us conceptualize this notion further by elaborating how one might treat teaching as scholarship. He suggests three characteristics. One involves connecting teaching to the discipline: making it part of the responsibility of the disciplinary community. The second requires that teaching become visible through artifacts, just as we use manuscripts and presentations to make visible our research; a frequent suggestion is the use of teaching portfolios or dossiers for tenure and promotion. The third requirement is that these artifacts be peer reviewed, judged by those beyond the office next door. The result of these kinds of activities could be the creation of what Edgerton et al. (1991) call a discourse community.

In what follows, we begin to create this discourse community around a little acknowledged and rather opaque aspect of our teaching: supervision of the graduate student thesis or dissertation. This aspect of teaching is particularly worthy of our attention since it may be the area where we are least successful. Incompletion rates of students in doctoral programs (usually all but dissertation being completed) have been reported as high as $50 \%$ (Hunt, 1994). [While we recognize that there are many reasons for the high percentage of ABD's (e.g., financial, family, academic and personal), the role of the supervisor as inspiration and model cannot be underestimated.] 
The discourse community we are creating in this paper is first of all a community of two, ourselves. We hope it will be expanded to include you, the reader, your colleagues and the students with whom you work. We believe constructing this discourse is critical since language provides us with conceptual frameworks and categories to begin analyzing our experiences, to confront dilemmas in our practices, to make explicit our knowledge in context. And, potentially it can give voice to those with less power, the graduate students with whom we work.

\section{Background}

Let us begin by asking how the literature addresses this discursive element of the graduate student experience. Most studies are surveys, exploring the factors contributing to attrition or to student satisfaction. For instance, Friedman (1987) reported that of the graduate departments surveyed, about one third of students who complete their course work do not complete their dissertation. Goulden (1991) reported that graduate student assessment of the relationship/communication with the supervisor was a significant factor in how they viewed the overall dissertation experience. (Of note is that the roles described here are that of advisor and advisee, highlighting the confusion surrounding the distinct but overlapping nature of supervision and advising.) Overall, there appears to be general agreement that conflicting expectations and lack of clarity about expectations are critical factors in the dissatisfaction or attrition experienced by students. If we acknowledge that the supervisory relationship is a comradeship of extraordinary intensity (Phillips, 1979), then as supervisors we bear personal responsibility for creating a discourse which will enable us to be explicit about this most private and illdefined aspect of our teaching. And we suggest that this discourse might also have an impact on graduate school curricula and policy.

Cole and Hunt (1994) edited a volume which includes the stories of nineteen educators who traversed the doctoral journey. Among the dominant themes of these stories was the relationship between the student (traveller) and thesis supervisor (guide). Although each story was written by the individual in the traveler role, they state: "This relation is so vital that it needs to be clarified, negotiated, and continually considered by 
both parties" (p. 162). We too believe that both parties should be included in an interactive consideration of this process. We are not aware of any research where the teacher and guide have consciously co-constructed their narrative. Given this background, we believed that even a retrospective account over some distance of time would be a valuable addition to the growing interest in demystifying the thesis process.

In doing the conscious reflection that initiates this discourse, we are taking some professional and personal risks. As Davis (personal communication) has suggested, some of our reflections could serve as a shock to the assumptions about the nature of the doctoral dissertation research, and about the intellectual relationships and influences on supervisor and graduate student.

What are some of these tacit assumptions? One, the doctoral dissertation is an original piece of research by the student. Two, the supervisor has in some respects an arm's length relationship because of the intellectual property rights of the student's work. Three, the supervisor and the other committee members are experts, whereas the student is a novice being initiated into the culture of the academic and research worlds. Four, the thesis process is the same, regardless of the program and the goals of the student.

On a personal level, we recognize that teaching in its various forms has to be rendered in public ways. The reality for us is that practices do not always live up to expectations. That may be one reason for the paucity of research on this topic. The courage of our convictions is stronger than the desire to "look good."

\section{METHOD}

The activity of 'our' thesis process originated more than twenty years ago. In order to (re)capture our sense of the context, players, perspectives, activities, and consequences over these many years, we recently sat together in Toronto for a day and a half to talk with each other. We chose to undertake this activity because, over a number of years, we had had many informal discussions in which we revisited our shared experience to understand and learn from it. We speculated that our musings might be of 
interest to a broader audience, other professors like ourselves. We therefore met specifically to re-contextualize ourselves in the time and place of this shared relationship. We then co-constructed a distillation of our many unrecorded conversations through the formal structure of a recorded dialogue during which we imagined an audience beyond ourselves. Our purpose was to (re)story our experiences by co-constructing a narrative that included anecdotes which enabled us to grasp several of the points along our journey (Van Manen, 1990). Narrative method has become a useful form of inquiry in the human sciences (Kreisworth, 1995). Noddings and Witherell (1991) remind us about stories:

They provide us with a picture of real people in real situations, struggling with real problems...they invite us to speculate on what might be changed and with what effect. And, of course, they remind us of our persistent fallibility. Most important, they invite us to remember that we are in the business of teaching, learning and researching to improve the human condition (p. 280).

The co-construction of narratives has become a useful tool for studying the lived experiences of individuals who may have different roles and/or perspectives (Florio-Ruane, 1991; Lather, 1994; Strauch, 1995).

Prior to having our conversation, each of us wrote a description of our backgrounds and our recollections of our relationship to resituate ourselves. We agreed that the conversation would be bounded by a focus on the academic. In other words, we did not enter into the personal while recognizing that the personal and professional aspects of the dissertation journey are intertwined. In this way, we hoped that our experiences might better resonate with those of other professors who themselves had been previously graduate students. Then we taped our conversation in the cafeteria where we had met many times over mugs of herbal tea. Then, we went our separate ways to transcribe the conversation and to write various portions of the manuscript. Some of the factual information such as dates and individuals was retrieved through reference to institutional and personal files. We separately reviewed the transcript and then wrote about issues, enigmas, and implications arising from the 
process. The final product was a negotiated (in the best sense of the term) understanding of our experiences.

We recognize that the lengthy passage of time is a potential problem in this type of work. And a reader might ask why we did not choose, for instance, to have a conversation about our collective experiences of the supervisory role, which would represent more recent phenomena, and might bring forth other issues. Our response to this critique would be that although such an undertaking would be very valuable, it would not represent a deconstruction of our joint, shared experience of the same events; nor would it be possible to represent (at some distance) the experience of these events through the eyes of a graduate student.

We edited the text to make it shorter than the entire dialogue. However, both of us agreed to depart from the usual convention of selecting some portions interspersed with discussion of the text. Here, we present the edited text as a continuous dialogue followed by interpretations of some of the issues deemed important about the thesis process. Although the editing process itself is an interpretive act, it was our belief that the remaining dialogue run in its entirety would remain faithful to the holistic perspective of our conversation.

\section{Our story}

Lynn: At the time our story began, I was a teacher of adults, a teacher trainer and a materials developer working in Montreal. I had always enjoyed learning and found it quite natural to seek out formal opportunities for professional development. As a result, I had done my master's degree on a part-time basis. In this process, I felt ambivalence since the course work had pushed my boundaries in positive ways, but the epistemology and the design of the thesis (positivist) had called into question the value of my epistemology of practice. At that time, I did not feel called or even attracted to the academic life - I saw myself as a practitioner who wanted to improve my practice, be more effective in my own setting. So, after completing my master's, I looked around for further learning activities and heard about the doctoral program (Ed.D.) at OISE designed specifically for practitioners, not academics - I thought (hoped?) it would meet my needs. And so I began my studies 
there in the summer of 1976 . I have subsequently become a faculty member at McGill University where I also supervise graduate students.

Joel: I arrived at OISE eight years before meeting Lynn and had joint appointments in two departments: Curriculum, and Measurement and Evaluation. Although my masters degree was in educational psychology, and I specialized in testing and evaluation for the doctorate, I wanted to integrate my interests in curriculum with program evaluation. I came into educational research through a circuitous route. A chemistry major as an undergraduate, I worked as a laboratory technician and supply chemistry teacher for several years. Thinking I was more interested in forensic chemistry, I asked a former social science professor for a recommendation for law school. His antennae were sharp enough to detect lukewarm commitment on my part, and he suggested that I apply to his alma mater to pursue a degree in educational research. My intellectual curiosity blossomed at this major centre for educational research, and I was fortunate enough to work with a legendary researcher. My own thesis was completed a year after coming to OISE, a situation which made me acutely aware of the problems of leaving before completion. When I met Lynn, I had had experience with a number of doctoral students and had supervised ten students to that point.

\section{OUR CONVERSATION (JANUARY 31, 1997).}

Joel: I wonder if you want to tell how we started our relationship.

Lynn: Hard to retrieve after 20 odd years, but we got to know each other by my having an office next door to you, when I first arrived... You were friendly...that led me in the fall to join a group of students working with you and a colleague on a journal published by OISE.

During the year while I worked with you, I did my course work and kept in touch with the advisor who had been assigned to me when I entered the program...I was interested in the areas of program development and implementation, and teacher education. The opportunity came up in the winter to take a course jointly taught by you and a colleague in program evaluation. There were only two other students so it was quite an intimate experience - overall, stimulating and challenging - but not necessarily representative of my experiences of course work. 
There were at least two courses about which I was quite unhappy because of the way in which my personal practical knowledge (at that time there was no such name for it!) was represented within the context of curriculum studies. As a result, I wasn't very positive about the extent to which I could marry my personal/professional interests with what appeared to be demanded of me in these courses. I felt sometimes that my professional knowledge was not being validated, but rather being denigrated... and other students shared my impressions.

Joel: So, in some ways, you were skeptical — probably wondering whether or not you belonged or whether you even wanted to belong.

Lynn: Yes, it was a question of me not being a knower...feeling I wasn't sure I could fit into what was being expected of me. And...I hadn't ever lived the life of a full-time graduate student where I might gradually by osmosis have become knowledgeable about the discourse that surrounds the relationship between faculty and between faculty and graduate students. For instance, at that point, I wasn't even aware of the difference between the roles of advisor and supervisor because they had been represented in the same person for me at the master's level, and I didn't understand that supervision entailed workload responsibility. And, there was nothing in the program that helped me or others understand any of that. Looking back, I wonder if the assumption was that many of us had this knowledge already...or... that this knowledge was so tacit for those living in the environment that it wasn't even discussed - there wasn't the language.

Joel: ...Also, what it meant to be a graduate student at that time (the mid 70s) was also problematic. The kind of discourse we have today seems to be more open...more conscious. I am now teaching one of those courses, and one of the things I've picked up on (probably from the experience with you... and other students as well) is that the talk of demystifying the thesis becomes just as important as the conceptualization of curriculum problems and how to develop methods.

But it seems to me, in going back to our relationship that there was probably a point in the course on theory and policy of evaluation where we might/must have gone further in our relationship...to the kinds of discussions that you were interested in and that I was increasingly interested 
in at that time, even though I had had a fairly traditional training myself in my Ph.D., and probably would see myself more as a researcher than a practitioner. However, my involvement in evaluation was my link to practice, not just theory and generation of theory. So part of teaching some of these courses (such as alternative forms of evaluation) was the struggle I had with the notion of theory and practice. And being in two different departments, I really struggled with how you make the connections, how to do it in a particular context. It wasn't my training, but my teaching, my reading, my working with students' inquiry into their own practices. It was my growing awareness of how you could look at evaluation as an educational process both in abstract and real terms. My experience and your interest...I was interested in your topic, but also I was struggling with those ideas myself.

Lynn: ...I can see that our interests would have generated an intellectual conversation of some kind .... and it's easy to forget the big shifts that have occurred since then, not just in the integration of theory and practice, but also in terms of what was considered acceptable research. Having done my M.A. in a department where the positivist paradigm was predominant (in fact, like most departments and faculties of education at that time), I knew quite clearly that that was not what I wanted to do because I felt it wouldn't help me understand my practice better. So, probably my feelings about that may have been another intellectual link for us since you were exploring qualitative approaches.

However, during that year I was very much tied up in my course work, and after fifteen months, I had to return to my work. Of course, I was immediately embedded in that practice which I saw as MY practice...I got engaged in an evaluation project at my work, and I began to document it trying non-traditional approaches. I was interested in what would happen. I didn't know if it would become my dissertation, but I had enough of a sense of its importance in my practice as a professional that I wanted to be able to track it.

Joel: It was very concrete which I sensed was very important to you - to ground whatever you were doing. But let me go back a bit. There were changes taking place in the discourse in curriculum, and I was aware of them and struggling with them - Pinar, Apple, Freire's work, 
and a bit later on - what really helped was Schon - reflective practitioner - had a major impact on me in terms of understanding the nature of what we do as researchers/academics/technical rationalists, but also in starting to look at what we do - our own practice.

Lynn: Yes, but that's leaping ahead to 1983 ...It was a very profound book for me too. I was actually nearing the end of the dissertation process at that point and I remember reading Schon and having this AHAA! experience - here was someone who in a different way was describing what I had been trying to name myself, to understand the principles driving my practice...but this is leaping ahead, dear reader...

Joel: You're absolutely right...but part of the issue is that neither you nor I were necessarily stagnant and part of the process that made it difficult was that both of us were struggling and I admit, in fact, celebrate, that I was thinking and changing...over time - so there were good reasons that so much time elapsed...but going back...

Lynn: So...I still didn't have a supervisor, and I still wasn't clear on the difference between a supervisor and an advisor - I realized I had to do a proposal; I was continuing conversations with you and also with the advisor I had been assigned... and by the summer of 1978 I was actually working on a proposal, and I spent the summer at OISE working on that, meeting with you and my advisor... and near the end of the summer you initiated a conversation with me...

Joel: Yeah, we had been spending a lot of time together, almost a daily conversation...you struggled with what a problem of inquiry would be, and my task was to help but also to understand something about the nature of the conceptualization of evaluation and education how they are related to each other...evaluation as an educational process... and it came to my attention that we were spending a fair amount of time together when someone asked, "Are you her supervisor?" And I said "Well, I don't know, I'm not the advisor" - so I initiated the conversation...like: "We've been working together, at some point you have to make a decision about a committee, the most important decision is about the supervisor"... and I guess my feeling at the time was that it was your decision, but at the same time I also felt we 
had come a fair way in intellectual engagement, and thought that might be the way to go, but it was entirely your own decision...

Lynn: And I now have great difficulty retrieving exactly why I found this problematic - I think it's because I still didn't understand the difference between the advisor and supervisor - I still didn't feel like a knower. I seemed to be getting disparate information from different people about a process I didn't understand, and I found it very difficult....but...the change was made and the proposal was approved, and so we began the process of the dissertation. Maybe you have some recall of these events...

Joel: ... It seems to me that it was more problematic than it should have been... unfortunately it put you in the place of trying to interpret the culture when in fact I should have been more clear and handled the circumstance among colleagues. I'm ambivalent about that since it's an important decision for a student - it would almost make the student infantile...

Lynn: I agree with you - I don't think I would have felt comfortable for you to have gone and dealt with the issue among colleagues. Part of the student's role is having control over those decisions. I think if I could put myself in your shoes, it would seem that I needed a clear explanation of what a supervisor is, how supervision relates to the intellectual journey, how it is recognized as a teaching activity and awarded credits. All these things were still not apparent, and I think that if I'd had the knowledge, it probably wouldn't have seemed as difficult as it did.

Joel: I think I probably explained the difference between the advisor and supervisor, otherwise we couldn't have had the conversation... What I didn't do was make it clear that's it's all part of what it is to be a professor, and it's related to credit, but that's certainly not the issue...My concern was that this was worth it because I had intellectual capital in it, and so one way of getting a reward was to be your supervisor

Lynn: ... So, now we get into... what that journey is and the difficulties of the journey...that you don't know what the end is... and assume that the supervisor in some ways understands the journey because he or she has travelled it personally as a student and also a number of times as a supervisor/mentor. And I guess before we talk about that and the difficulties entailed in the intellectual journey, it's important to mention the 
context in which we worked from then on, which would probably have been 1979 (when the proposal was accepted) until believe it or not 1985 . I was in Montreal and [you were] in Toronto and I would manage to get to Toronto most summers for three to four weeks...During the time I was in Toronto I was able to work just on my dissertation and have daily contact - I got loads of feedback and then when I was away I'd get immersed in my practice, it would take longer for me to do things - I'd make a leap forward in the summer and then I'd stumble and fall during the year to try and make another leap forward the following summer. So, there was that cyclical process you call peaks and valleys and I call feast and famine...

Joel: ...I want to say something about the nature of the thesis itself - it was unusual in several ways. It was not your usual problem, hypothesis, method, analysis, conclusions study.

Lynn: Was it your first of this kind?

Joel: I'm trying to remember - there was one in higher education who did in some ways a study within a study - I'm blanking on the time but it was certainly something I was starting to work on with other students, and you may have been the first for the initiation, but there may have been others in the interim before you finished.

Lynn: That wouldn't have been hard since it took me so many years to complete.

Joel: So, there was the notion that it was different - the idea of trying to deal with a movie within a movie, a study within a study and all that that entailed - collecting the evaluation information on the reading lab...which was only the basis for studying the whole process (of your practice).... You came up with very different levels in the thesis, which complicated matters. We were both struggling...And it reminds me of something I heard Lee Cronbach say a number of years ago, that it is unfair to graduate students to allow them to do case studies... So we have a number of different things that are impacting, aside from your point that it's very difficult to complete a thesis when you are away from the university, from the culture of the day-to-day context - in isolation. I think that it's very important - these different kinds of isolation - you had your own isolation and even coming together there's a form of isolation 
from the culture, and you probably had some thoughts like "Who needs this," and, "I think that's important." So, one of the things I wish you would talk about is your skepticism about the nature of academic work...

Lynn: I guess what you are probably referring to is a conversation that we both recall quite vividly. It had to do with my rootedness in my practice at that time... Today I'm still amazed at being an academic. But at that time I was still struggling with the idea that the academic world didn't necessarily validate my world of practice. That was partly a result of my course work, partly the fact that I was having to do so much literature review to defend the decisions about the [dissertation] approach $I$ was using.... So one day we were sitting talking and I think I accused you of being unable to see through my eyes, unable to see my professional practice and the concerns I had around that, and you responded quite irately - what did you say?

Joel: I don't know if I was irate - I thought I was being as calm and collected as possible...But...I wanted to disagree with you..."you know there are different kinds of practice and right now we're participating in my practice and I think there are some connections - as a professor one has practices that deal with teaching and learning - actually the substance of what we're dealing with here"... and I intuitively understood that and felt your concern and frustration... which is fascinating because I couldn't explain that to you at that time...I think I was probably not sophisticated enough and knowledgeable enough to be able to develop it and go further, and that's where ten to twelve years later...

Lynn: ...I agree that you do have a practice (me too) though not the same kind of practice. But I think in terms of our relationship at the time, the conversation didn't get me any further... and I think it's like the secretary who complains to you about her boss and you say "oh yes, I really understand your situation because I also have those kinds of situations..." It didn't help me deal with...the anger, the anxiety I was feeling of not knowing how to proceed...

Joel: Let's take up the issue of the kinds of interactions that characterize most of these relationships, and really, we were in many ways a community of two... are there other instances that characterize your feelings about being a student, partly realizing that I was in control...but 
also in terms of wanting feedback, and not getting it when you wanted because after all you had spent a lot of time on it...

Lynn: And, like all graduate students, I wanted immediate feedback...

Joel: That's right, and what you do is line them up as best as you can - in chronological order - when they come in... Given the fact we're much more aware of power and control - can we talk about it at all?

Lynn: Sure - though I don't think about it as a personal issue since you were warm... and demanding! Remember, this was back in the late 70 s - faculty members basically were all male; I ended up with a committee that was all male, probably 10 years older than me - I still didn't feel a knower. I think that gender and age and lack of knowledge (and probably partly my character) made it difficult for me to challenge, to ask questions, to feel more a knower...and, as I say, I don't think that was your fault. I think it was my inability to understand the influence of those factors on my loss of voice or my trying to find a voice. Part of that, too, was not knowing where the journey was leading me, and expecting that you did know or trusting that you did... and yet the journey was never revealed to me ahead of time. I've come to realize in my practice of supervision (as well as my experience as a student) the importance of talking about the journey...I can say "you're on the right track even if I don't know where exactly the journey will end"..."this process is like...traveling up a river and not knowing exactly where you're going to end up but knowing that you are progressing".

I think we've also mentioned the fact that you weren't quite sure where the journey was going to go because it was new for you and was part of the intellectual stimulation... which leads back to that whole idea as to who really owns the dissertation. You know, the myth is that the dissertation is a piece of original work, and I think in some senses that's probably true from the perspective of the student who's done that work, knowing more intimately and in greater detail than anyone else...but I think we both feel that a lot of the dissertation process is really a coconstruction within a community of two... and you're right, part of the pleasure, the joy of teaching in supervision, is all that intellectual stimulation, and the person becoming a colleague in the process...would you not agree that it's a co-construction? 
Joel: Absolutely... and while it was in fact your thesis, and you were basically an apprentice in terms of the thesis process, you weren't a novice in a lot of things that you were involved in - nor was I always an expert...since I had to understand your practices and something about a new and different way of thinking about how one goes about studying a problem of inquiry both in terms of substance and of form.

I want to take up the issue of what Purkey calls invitational learning...it's increasingly my aspiration ( and I've changed quite a lot in my relationships with students in the sense of moving away from being an all-knowing professor to the recognition that I'm a person and we're in a relationship with each other)...I'd like to think that while I may have seemed and probably was very difficult...that I treat people... so they will feel invited to engage with me and feel open if there is a problem...they'll come.

The problem... is that we each come with a set of prior experiences - reminds me of Gadamer's fusion of horizons - the dialectic among what we bring from the past, and the present context, and always looking to the future - so those three things sort of intersect at one place...so part of the issue is that students bring their own expectations, either from their own past or what they pick up from the culture or what appears to be the culture (much of what is picked up from observing things - like some of your experiences in class).... and I think that you were absolutely appalled by it...so, what I'm saying is the issue of power and control doesn't have to be so blatant - it's very subtle...

Lynn: Yeah, I agree totally with you, there were social and cultural factors strongly influencing our personal interactions...

Joel: Yeah, and...the point is that there may be an institutional culture, but it may also be that the professor has a different expectation from the student. So how do you deal with all these things - your own past experience, what's actually going on presently, and the culture of the place... and also what you have lying ahead of you - what the future holds?... To be frank with you, in my own thesis work, I had some real disagreements with my faculty advisor on some things...

Lynn: Your advisor or your supervisor?

Joel: My supervisor, thank you. 


\section{Lynn: ... The difficulties of terminology!}

Joel: Well, he was both my advisor and supervisor and after about the third or fourth draft I wasn't arguing, even if I didn't agree with him, I just made the changes that he wanted because I wanted to get out... so we all make our own compromises...

Lynn: Yeah...yet I don't think that power and control were essentially personal issues but based on roles, context and previous experiences. These days I like to think about Daloz's notion of mentoring...the mentor having three functions - providing vision, challenge and support. And I think you were very supportive at a personal level, and I kept feeling you had the vision, though I didn't know what the vision was... and you were certainly challenging because every time we'd meet I would go off with these pages of things I should be thinking about... and that's probably what kept me at the process, the challenge...because that's the journey, isn't it? It's learning new things, otherwise why bother!? So, I think that was a critical element in keeping me going....and you did continue to work with me until at some point you felt that this might never end, that I might never give up...so when did that happen?

Joel: Probably the year before your final draft - you say you don't remember it, so you can't disagree with my recollection...

Lynn: It was either so traumatic that I have erased it...or you were always challenging me and I just interpreted it as one more challenge!

Joel: I said, "Lynn, it's really unfair to you"; it seems to me in part it was a statement about myself as well, I was very unhappy about it, I was saying "look if it doesn't work in this draft perhaps it's not worth continuing"... and I guess it comes back to co-construction...co-construction is an abstract activity which doesn't really speak to any emotionality or affect... but it is an affective thing for me anyway...there's a sense...dare I say it of being a parent, having a child and being proud of the child, but also realizing that it is not only the child but also the parent involved. And I basically said to you, it's fish or cut bait... and absolutely you came through. The next draft was really quite good and I was really quite proud of you...in some ways it's an irony here...

Lynn: Yes, definitely... since I never saw myself as an academic... 
Joel: ...But that's the irony of it - there may have been times that I might have thought - quite apart from my judgment that you were very bright, that you were academically interesting and interested - that perhaps it was not for you...

Lynn: ... and I guess I don't see any reason why you shouldn't feel proud of the thesis because of the co-construction that was involved...

Joel: Completing also meant, though, that you had passed the hurdle...You managed to come up with something that we both were happy with and that the institution was happy with. That's the other issue about the community of two and the isolation of it. This is where the faculty member has to use his or her prediction or understanding of the context in terms of what's acceptable or not - just because we agree doesn't mean that others won't have some question... but you both agree it's ready now to go beyond the community of two - the isolation, the cucooning is over - it's now open to public inspection - increasing layers of public inspection...

Lynn: Mmh...You asked me the other day how I felt after the oral, which was in some ways the formal end of the journey, and I answered - exhausted!! I recall, however, feeling very happy when I finally deposited all the copies for distribution to the committee (before the oral)... and I think it was because somehow between the two of us we had resolved some of the issues that had been creating tension for me from the beginning - the tension between theory and practice, the tension around appropriate research methods - those acceptable to the academic world and to me.

And, you're right - My practice has changed dramatically, though incrementally, from ten years ago...I find myself now... in your role as a supervisor (of graduate students)... and I enjoy this present practice very much, and enjoy teaching as a scholarly activity as I think you do... and that is what led us to have this conversation.

\section{HOW DOES OUR STORY SPEAK TO US?}

Earlier we mentioned four assumptions, tacit precepts underlying supervision. We believe our story speaks to each of these. 
The doctoral dissertation is an original piece of research by the student. Our experience of co-construction within the community of two tells us quite clearly that this assumption is not true. We even talk about "our" thesis work and Joel's investment in the "intellectual capital". In other words, although the thesis is an original or novel piece of work for the student as it is the first time he or she has ever completed this journey, it clearly could not exist without the collaboration of the supervisor and later the committee.

Lather (1991) has talked about the social relations of research, that the relationships among the people involved mediate the construction of knowledge. What we have in the supervisory experience is a movement or shift in power among the people involved as the graduate student slowly develops voice and thus more power. We suggest that the thesis represents the predominance of the student's voice filtered through the supervisor's lenses.

Supervision is, in some respects, an arm's length relationship because of the intellectual property of the student. Both of us recognize the importance of the personal in the thesis process. The warmth, the shared intellectual interests, the struggling with ideas all contributed to a friendship that has endured for more than fifteen years after the journey ended. Both of us can see quite clearly that what Joel characterized as the "affective thing" was critical in sustaining our efforts.

The supervisory relationship has been characterized by one of our colleagues as meaning "my work really does matter." In contrast with teaching courses with large numbers of students for short periods of time, the thesis process provides the intimacy of a privileged relationship in which we work closely over time with someone who is engaged in the same intellectual journey as we are. And, how many of us as researchers have the opportunity for this kind of colleagueship outside of the supervisory relationship?

The supervisor and committee are experts whereas the student is a novice being initiated into the culture. In some respects our experience validates this assumption, and raises for us several questions. Joel sometimes characterized the relationship as that between a parent and a child, perhaps because he is a parent, and Schratz and Walker (1995) 
describe graduate student accounts of their experiences as having strong overtones of relationships between children and their parents. Lynn described her experience as not being a 'knower,' and was in fact somewhat skeptical about the extent to which she wanted to become a member/an expert within the academic culture. Issues related to power and control were most evident here (age, gender, knowledge) where institutional constraints come most into play. At the same time, Joel makes it clear (though was it clear at the time?) that he also was not a knower. He acknowledged that he had things to learn about Lynn's expertise if we were actually to co-construct the inquiry, and also things to learn about supervision and the conduct of research. This leads us to query the appropriateness of a cultural practice in which graduate students (without their explicit knowledge) become by default a new faculty member's closest colleagues, and often the principal sources of our learning about research (McAlpine, 1999).

Nevertheless, what is occurring during the co-construction is the gradual liberation of the students from the necessary support and guidance of a mentor towards a clear independent voice of their own. It is important to note here that our recollections and musings about the socialization process concentrated on the community of two, and have included limited references to others and to institutional social practices. Mullen and Dalton (1996) remind us that the thesis is part of the big picture of socialization within graduate school. Their chosen metaphor, that of sharkdom provides a vivid message of how speaking mostly to the personal may seriously distort the socialization process. Both Mullen and Dalton illustrate the lived contradictions of having excellent personal experiences with supervisors, but expose other features of the social relations which work against effective socialization. Put another way, their work may indicate the limits of the community of two if the supervisor cocoons the student from the larger culture and/or cannot help to control those other institutional experiences.

This again raises issues about the type of expertise required for supervision, which, at a minimum, should include both knowledge of the graduate school culture and skills for overcoming the legitimate and pernicious aspects of the setting. This is a two-way street: students should recognize 
and acknowledge the limits of faculty in their own culture, which is useful information for those wishing to take up posts in the academy.

What we are noting here is that the intimacy of the supervisor-supervisee relationship makes the supervisor in some ways the gatekeeper or border guard into the world of academe, a particular culture with its own discourse and interaction patterns (Becher, 1989). The student can use the supervisor as a cultural broker (at the customary border crossings and in culturally appropriate ways). He or she can also choose alternate methods to become a 'knower', guerrilla tactics such as student support groups, to enter the new country and learn about its culture. Here, the assumption on the part of students is that as a group they are (and can become more) knowledgeable about the culture. Chances are that students today probably do both. We take up the issue of borders again under the next assumption.

The thesis process is the same regardless of the program and the goals of the student and supervisor. In our story, Lynn stated that she was attracted to the practitioner-oriented Doctor of Education program at OISE, a degree for highly-placed practitioners who would use their professional context as the site for their inquiry. This was in contrast to the $\mathrm{Ph} . \mathrm{D}$. for those interested in academic/research careers. The reality for Joel has been that there are not clear-cut distinctions for each of the two types of theses. It is his impression that most of his colleagues share his operating view that the standards for the process and product are the same (a view that probably has been fostered by the emergence of qualitative, personal, action-oriented methods as legitimate alternatives for both types of thesis). Lynn's experience as an academic affirms this. In her institution, she has participated in discussions with colleagues about unresolved issues related to the nature of the differences in theses and dissertations between the M.Ed. and M.A. degrees, between the Ed.D. and Ph.D. degrees, and occasionally between the M.A. and Ph.D. degrees.

In many respects, we have documented a unique experience, a process distinct from any other. For instance, the nature of the inquiry, a study within a study, is not a common feature of theses. Nor perhaps is the fact that Lynn had only ever experienced part-time graduate study, and wanted to remain a practitioner rather than become an academic. 
Similarly, Joel brought unique experience and expectations: a desire to explore new ways of thinking about education and evaluation. These special characteristics speak to the uncharted ground where graduate students and their supervisors sojourn while working on 'their' theses. At the same time, the very uniqueness of each individual's experience tells us that isolation must be, in fact, a very ordinary feature of the experience, and indeed we documented a range of forms of isolation.

To return to borders, if we take up Giroux's (1992) idea of border crossing, the explanation for this isolation can be seen as one of difference and power. The student is negotiating new terrain, new cultural codes and discourse, having left behind the comfort and the power of the known culture and experience. This involves risk-taking. The supervisor undertakes to initiate the student into conformity with the culture and ultimately into a sharing of the power. At the same time, in the best of practices, we believe that the supervisor needs to be prepared to negotiate with the student new ways of seeing his or her own culture. This latter may be more a product of hindsight than the reality at that time.

\section{CREATING CLOSURE}

We initiated this immediate collaboration because we were struggling with writing about Lynn's thesis. It became apparent that issues surrounding our collaboration on the thesis process were of greater interest to us than any products from the thesis. Connections were made to the emerging discourse on teaching as scholarship. What struck us is that the discussion was focused on what went on in the classroom, a not unheard of starting point. The energy behind this 'improvement' comes from Boyer's (1990) report on scholarship and renewal of priorities of the professoriate. Reactions to the inclusion of teaching as a legitimate form of scholarship have included thoughtful questions about the criteria and characteristics of this activity (Cunsolo, Elrick, Middleton, \& Roy 1996), and a call for a new epistemology for the university community (Schon, 1995). Consistent with his long-standing critique of technical rationality, Schon believes: "If teaching is to be seen as a form of scholarship, then the practice of teaching must be seen as giving rise to new 
forms of knowledge" (p. 31). He calls for the legitimacy of action research as a form of inquiry essential to describing and interpreting the community of inquiry.

Our community (graduate school) includes complex activities considered under the teaching rubric. We chose to go outside the classroom and describe an example of a 'community of two' involved with the thesis production process. Through retrospective activity, we have undertaken a reflection-on-action of our practices. We see this as less self-indulgent than an opportunity to participate in the growing discussions of the many forms of teaching and ways of understanding teaching practices. We would encourage others to join this discourse by adding their own examples and contributing to the methods by which we come to understand this form of scholarship. Just as in any interpretive activity, we have been selective about what we have chosen to reveal. There is less of our own personal circumstances in our accounts (e.g., childrearing problems, chronically-ill husband). Others engaging in this process will have to make determinations about the relationship between the personal and professional.

We are reminded of the three faces of knowledge suggested by Schwab to be in symbiotic relation to each other when considering curriculum translation. The first is the knowledge itself; the second, the means by which we come to produce such knowledge; and the third consists of the arts of communication which allow us to know about the preceding two faces (1978). Our conception of scholarship addresses the areas of expertise that should come into play during the mentoring process of the thesis journey. It is also our belief that a concern with the curriculum of graduate education necessitates the inclusion of research which addresses all three faces (Weiss, 1999). We must describe our different teaching contexts, how we came to know them, and how we learn to communicate about both. It is only in this way that we can take up Shulman's challenge to explicitly treat teaching as scholarship. 


\section{References}

Aguinis, H., Nesler, M., Quigley, B., Lee, S., \& Tedeschi, J. (1996). Power bases of faculty supervisors and educational outcomes for graduate students. Journal of Higher Education, 67(3), 267-297.

Becher, T. (1989). The significance of disciplinary differences. Studies in Higher Education, 19(2), 151-161.

Boyer, E. (1990). Scholarship reconsidered: Priorities of the professoriate. Princeton, NJ: The Carnegie Foundation for the Advancement of Teaching.

Braskamp, L., \& Ory, J. (1994). Assessing faculty work. San Francisco, CA: Jossey-Bass.

Centra, J. (1991). Reflective faculty evaluation. San Francisco, CA: Jossey-Bass.

Cole, A., \& Hunt, D. (1994). The doctoral thesis journey. San Francisco, CA: Jossey-Bass.

Cunsolo, J., Elrick, M-F., Middleton, A., \& Roy D. (1996). The scholarship of teaching: A Canadian perspective with examples. The Canadian Journal of Higher Education, 26(1), 35-56.

Daloz, L. (1986). Effective teaching and mentoring. San Francisco, CA: Jossey-Bass.

Daly, W. (1994). Teaching and scholarship: Adapting higher education to hard times. Journal of Higher Education, 65(1), 45-57.

Davis, O.L. (1993). Personal communication.

Edgerton, R., Hutchings, P., \& Quinlan, K. (1991). The teaching portfolio: Capturing the scholarship in teaching. Washington, DC: American Association for Higher Education.

Florio-Ruane, S. (1991). Conversation and narrative in collaborative research: An ethnography of the written literacy forum. In C. Witherell \& N. Noddings (eds.), Stories lives tell (pp. 234-256). New York, NY: Teachers College Press.

Freidman, N. (1987). Mentors and supervisors. New York, NY: Institute of International Education. ED 295541.

Goulden, N. (1991). Report of the perceptions of communication and relationships during the dissertation process by speech communication doctoral advisors and advisees. ACA Bulletin, April, 39-48.

Hunt, D. (1994). Have you traveled this path before? In A. Cole \& D. Hunt (eds.), The doctoral thesis journey, (pp. 161-163). Toronto, ON: OISE Press. 
Kreiswirth, M. (1995). Tell me a story: The narrativist turn in the human sciences. In M. Kreiswirth \& T. Carmichael (eds.), Constructivist criticism: The human sciences in the age of theory, (pp. 61-87). Toronto, ON: University of Toronto Press.

Lather, P. (1991). Getting smart: Feminist research and pedagogy within the postmodern. New York, NY: Routledge.

Lather, P. (1994). The validity of angels: Interpretive and textual strategies in researching the lives of women with HIV/AIDS. Qualitative Inquiry.

McAlpine, L. (1999). Becoming a researcher: Reflections-on-action. Paper presented at the annual meeting of the American Educational Research Association, Montreal, QC.

Mullen, C., \& Dalton, J. (1996). Dancing with sharks: On becoming socialized teacher-education researchers. Taboo: The Journal of Culture and Education, 1, 55-71.

Noddings, N., \& Witherell, C. (1991). Epilogue: Themes reminded and foreseen. In C. Witherell \& N. Noddings (eds.), Stories lives tell, (pp. 279-280). New York, NY: Teachers College Press.

Phillips, G. (1979). The peculiar intimacy of graduate study: A conservative view. Communication Education, 28, 339-345.

Schön D. (1995, November). Knowing in action: The new scholarship requires a new epistemology. Change, 27-34.

Shulman, L.S. (1993, November). Teaching as community property. Change, 6-7.

Smith, S. (1991). Report of the commission of inquiry on Canadian university education. Ottawa, ON: Association of Universities and Colleges of Canada.

Strauch, G. (1995). Lifting a veil of silence: Teachers and doctors talk about death. A narrative approach to death education. Unpublished doctoral dissertation, University of Toronto.

Schwab, J. (1978). The practical: Translation into curriculum. In I. Westbury \& N. Wilkof (eds.), Science, curriculum and liberal education, (pp. 365-383). Chicago, IL: University of Chicago Press.

Van Manan, M. (1990). Researching lived experience. London, ON: The Althouse Press, The University of Western Ontario.

Weiss, J. (1999). Strangers no more: Researchers studying their own learning environment. Paper presented at the annual meeting of the American Educational Research Association, Montreal, QC. 